\title{
Is drinking alcohol associated with sexual coercion among Ugandan university students?: a cross-sectional study
}

Devika Mehra $^{1,3^{*}}$, Anette Agardh ${ }^{1,2}$, Martin Stafström ${ }^{1}$ and Per-Olof Östergren ${ }^{1}$

\begin{abstract}
Background: Sexual coercion is prevalent in sub-Saharan Africa and is a risk factor for unintended pregnancies, sexually transmitted infections and mental health problems. Alcohol consumption patterns have been suggested to be an important factor behind the experience of sexual coercion among university students.

Objective: To study the association between alcohol consumption and the experience of sexual coercion among Ugandan university students.

Method: In 2010, 1954 Ugandan students participated in a cross sectional survey, conducted in Mbarara University of Science and Technology (72\% response rate). A self-administered questionnaire assessed socio-demographic factors, alcohol consumption, mental health, and sexual behavior. Multivariable logistic regression analysis was used to examine the various predictors of recent experience of sexual coercion. The data were stratified by sex.

Results: Of the 1954 students, 27.6\% reported having experienced sexual coercion and 16.4\% stated that they had such an experience recently. Individuals who reported frequent consumption of alcohol, or having consumed alcohol often on the occasion of sexual intercourse, were found to have a higher probability of recent experiences of sexual coercion (OR adjusted 2.29, 95\% Cl 1.40-3.72, and OR adjusted 2.78, 95\% Cl 1.56-4.97, respectively). These associations were significant even after adjusting for potential confounders. A synergistic effect was found between poor mental health and frequent consumption of alcohol in conjunction with having sex with regard to its impact on recent experiences of sexual coercion.

Conclusion: We found an association between alcohol consumption and experiences of sexual coercion among Ugandan university students. Therefore, universities may want to consider alcohol prevention under their policy framework, as it could reduce the potential risk of sexual coercion.
\end{abstract}

Keywords: Sexual coercion, Alcohol, Mental health, Uganda, University students

\section{Background}

Sexual coercion is a human rights violation and an important public health concern [1]. It has broadly been defined as any situation in which one person uses verbal or physical means including the administration of drugs or alcohol, with or without the other person's consent to obtain sexual activity [2].

\footnotetext{
* Correspondence: devika.mehra@med.lu.se

${ }^{1}$ Social Medicine and Global Health, Department of Clinical Sciences, Lund University, Malmö, Sweden

${ }^{3}$ Social Medicine and Global Health, Department of Clinical Sciences, Clinical Research Centre, Lund University, Jan Waldenströms gata 35, House 28, Floor 12, 20502 Malmö, Sweden

Full list of author information is available at the end of the article
}

Sexual coercion can have serious physical, psychological and social consequences for the victims [3]. In the shortterm these consequences include unintended pregnancies, abortions, and risky sexual behaviors including early onset of consensual sex, multiple sexual partners, and inconsistent condom use [3-5]. The long-term consequences are mostly psychological which may lead to depression, anxiety, suicidal attempts, low self-esteem, low self-efficacy, and substance abuse $[3,6]$.

Most previous research among young people has focused on men as perpetrators and women as victims, but results from studies confirm that men are also victims of sexual coercion perpetrated by men and women [4,7-9]. Several studies in Cameroon, Ghana, and Uganda targeting young 
people, have found that sexual debut of women was coercive in nature, where men were the perpetrators [5,10-12]. According, to a Ugandan study among adolescents it was found that, $47 \%$ of the males report victim experiences and $25 \%$ of females report perpetrator behavior [9].

Previous scientific research has found that there is a high prevalence of sexual coercion in Uganda $[5,13]$. The magnitude of sexual coercion ranges from 5\% to 33\% among Ugandan university students [13,14]. Most of the research done worldwide on university students shows that sexual coercion occurs among people who know each other, especially in dating partners $[15,16]$. There could be several reasons for sexual coercion in Uganda, but the most primary reasons are gender power relations that favor men and older age in a relationship $[17,18]$. The subordinate status of women in Uganda limits their ability to negotiate sexual decisions, which correspondingly increases their risk to unintended pregnancies and other sexually transmitted infections (STI) including HIV, which has a high prevalence in Uganda (7.3\%) [19,20].

In Ugandan university students there is a high prevalence of alcohol consumption, a survey done among students at six Ugandan universities showed that "nearly one quarter of all students drink, one fifth of those do so more than five times a month" [14]. Even though, Ugandan universities have a zero tolerance policy against drinking and no alcohol is allowed on campuses, students still continue to drink [21].

Alcohol consumption is a risk factor for sexual coercion among university students [22-24]. It has been seen in prior research that approximately $50 \%$ of all cases of sexual coercion involve the use of alcohol or other drugs by the victim or the perpetrator [23]. Alcohol is considered to contribute to the occurrence of rape in Ugandan universities both on and off campus [25]. In a Ugandan context, alcohol consumption may be part of a sexual control mechanism, which is used to obtain sex without the consent of the other person [26]. Sexual coercion can lead to risky sex, as it may not allow the victim to negotiate for safe sex. There are various theories which have been discussed regarding the association between alcohol and sex like alcohol disinhibition [27] and alcohol myopia theory [28]. The latter holds that restriction of cognitive capacity where the person focuses on the salient situational cues of sexual initiation and ignores the peripheral ones, thus limiting their ability to identify the potential dangers, including the risk of sexual coercion. Sex-related alcohol expectancies may influence drinking decisions and subsequently sexual risk-taking behavior among young people [29]. However, these theories have been discussed more in relation to the perpetrators than the victims.

Most of the research on sexual coercion has focused on sexual intercourse and inadequate attention has been given to the continuum of coercion acts, which could be non-penetrative. Lack of data on all types of sexual coercion skews our understanding of sexual coercion.

There is limited research in Uganda that has focused on the drinking patterns of the victims and its association with sexual coercion. Therefore, this study attempts to fill that research gap by investigating the association between alcohol consumption and sexual coercion among Ugandan university students.

\section{Methods}

\section{Study design and setting}

In April 2010, the data for this cross sectional study was collected at the Mbarara University of Science and Technology (MUST), a public university with four faculties: Medicine, Science, Computer Science, and Development Studies. The total university undergraduate student population comprised of 2706 individuals, out of which 1954 participated in the study ( $72 \%$ of all registered undergraduates). The respondents included 1087 males (55.6\%) and 867 females (44.4\%).

\section{Data collection and analysis}

All students at MUST were invited to participate in the survey. The study questionnaires were distributed to undergraduate students in the lecture halls. They were briefed about the purpose of the study and assured that their responses would remain confidential. Students were also informed that their participation was voluntary and they could withdraw from the study at any time. Consent forms were distributed, signed, and returned anonymously to a sealed box, as were the questionnaires. Contact details of the principal investigator and the research assistant was provided in case they had any queries regarding filling the questionnaire or had any personal concerns. The Institutional Ethics Review Committee at MUST approved the project.

Self-administered survey instrument consisted of an 11 page questionnaire with 132 questions on sociodemographic factors, socio-economic status, role of religion, social capital, alcohol consumption, sexual behavior other lifestyle factors, and mental health. The questionnaire in this study was same as the one used to survey students at MUST in 2005. It was based on validated instruments from other studies $[13,30]$ and on focus group discussions with young people [31].

\section{Definition of variables \\ Background variables}

Age was divided into two groups and coded as $\leq 22$ ('younger') and $>22$ ('older'). The median age of the students was 22 years, which was also used as the cutoff point.

Area of growing up was categorised as rural, urban and peri-urban, or small town. The variable was then 
dichotomised into 'rural' or 'urban', the latter combining urban, peri-urban and small town.

Educational level of head of household had response alternatives did not finish primary school, completed primary school, completed secondary school, post-secondary school, college, university education, and other. This variable was dichotomised as '>Primary education' or 'sPrimary education'.

The role of religion in family life while growing up was dichotomised into 'major' ('religion played a big role or was relatively important') and 'minor' ('religion was not so important or was not important at all').

\section{Alcohol use}

Alcohol consumption in the past 12 months was assessed by asking "How often have you consumed alcohol in the last 12 months?" There were five alternative responses: four times per week or more, two to three times per week, three to four times per month, once a month or less, and never. The variable was then trichotomised into 'abstainers' (never), 'infrequent users' (three to four times per month, once a month or less) and 'frequent users' (four times per week or more often, two to three times per week).

Heavy episodic drinking (HED) was based on the question "How often do you drink six 'glasses' or more on the same occasion?" The following alternative answers could be selected: daily, or almost daily; every week; every month; more seldom than once a month; and never. The variable was then trichotomised into 'abstainers' (never), 'frequent HED' (daily; or almost daily; every week; every month) and 'infrequent HED' (more seldom than once a month and never).

Alcohol consumption on latest occasion of sexual intercourse was assessed by two alternatives: 'yes' or 'no'.

Alcohol consumption on the occasion of sexual intercourse had the following response alternatives; always, or almost always, more often than on half of the occasions, about half of the occasions, more seldom than on a quarter of the occasions, almost never or never. The first three options were coded as 'frequent consumers of alcohol on the occasion of sexual intercourse' and the latter two as 'infrequent users of alcohol on the occasion of sexual intercourse'.

\section{Mental health}

The Hopkins Symptom Check List (HSCL-25) was used to assess the mental health status of participants in the survey. This scale consists of 15 items analysing symptoms of depression and 10 items assessing symptoms of anxiety during the week prior to the survey [32]. Furthermore, 10 items from the Symptom Checklist-90 (SCL 90) were included to measure symptoms of psychoticism during the past week prior to the survey. Each item was graded on a four point Likert scale [33]. Both of the above instruments have been validated and applied in different African cultural contexts $[13,34,35]$.

The total mean mental health scores as well as the mean scores of depression, anxiety and psychoticism were calculated from the student's total score for each measure. Scores were divided by the number of items for all the responses and dichotomised into 'high score' and 'low score', based on the median spilt between the total scores for each measure. The variables are referred to in the manuscript as 'poor mental health' and 'good mental health', respectively.

\section{Sexual coercion}

Experience of sexual coercion was measured by means of a validated instrument that has been used in previous studies on sexual behavior $[31,36]$. Experience of sexual coercion was based on response to the following questions: 'You have been forced to show your sexual organ', 'Someone forced you to let them touch your sexual organ', 'Someone forced you to let them suck or lick your sexual organ', 'Someone forced you to let them show you their sexual organ', 'You have been forced to watch someone masturbate', 'You have been forced to masturbate someone', 'You have been forced to take part in oral sex or to lick someone's sexual organ', 'You have been forced to take part in sexual intercourse with the penis in the vagina, or someone has inserted an object into your vagina', or 'You have been forced to pose for a sex photo or sex film'. If the respondent answered affirmatively to any of these alternatives, they were classified as being exposed to sexual coercion coded as 'yes', otherwise they were coded as 'no'.

Early experience of sexual coercion was created by combining the variables 'Age at first time of sexual coercion' and 'Current experience of sexual coercion'. We defined all those who reported that their experience of coercion happened before 18 years of age and those who did not report current experience of sexual coercion, as individuals having had an early experience of sexual coercion.

\section{Dependent variable}

Recent experience of sexual coercion was based on the response to the questions "How old were you when the coercive experience happened for the first time" and 'current experience of sexual coercion?' We classified all those who reported that their first experience of sexual coercion happened at 18 years or above, or were in a situation of current sexual coercion, as exposed to a recent experience of sexual coercion.

\section{Statistical analysis}

The statistical analysis was done using SPSS statistical package Version 20.0. We first calculated the prevalence of all the variables that were used within the sample 
population. Logistic regression analysis was then carried out to calculate the crude odds ratio (OR) with $95 \%$ confidence interval (CI), and determine the associations between the socio-demographic factors, mental health and alcohol consumption patterns (the predictor variables/ covariates) regarding recent experience of sexual coercion (the dependent variable).

The multivariable logistic regression analyses was performed to test a set of a priori stated hypotheses, thus the independent variables were chosen beforehand and forced into the model. A step-wise procedure was applied in order to reveal which independent variable, or set of independent variables, that actually made a clear impact on the outcome variable, rather than creating a "black box" by adjusting for all independent variables in one single step. Estimates of effect modification were done as "departure from additivity of effects on the chosen outcome scale". In addition, a synergy index (SI) was calculated [37] to disclose effect modification between the chosen variables, as proposed by Rothman [38].

\section{Results}

Table 1 gives the prevalence of all the socio-demographic factors, alcohol consumption, mental health, and experience of sexual coercion in our sample of Ugandan university students.

The age of the participants was dichotomized into $\leq 22$ and $>22$ ( $55.5 \%$ and $44.5 \%$ respectively). The participants who came from the urban background totaled $55.1 \%$ and from the rural area were $44.9 \%$. Approximately, $72.7 \%$ of the respondent's grew up in an environment where the educational level of head of the household had more than primary education and $27.3 \%$ had less than primary education. Approximately $28 \%$ of our sample had an experience of sexual coercion. We observed some gender differences, a larger proportion of females (33.9\%) reported such coercion compared to males (22.5\%). Approximately one-sixth of the sample had a recent experience of sexual coercion with a higher prevalence in females $(22 \%)$ compared to males (11.8\%). More than half of the students surveyed abstained from using alcohol in the past 12 months and less than one-tenth were frequent consumers of alcohol. The proportion of students consuming alcohol on the occasion of sexual intercourse was higher for seldom users (79\%) than frequent users (21\%).

Table 2 shows the bivariate associations between sociodemographic factors, alcohol consumption, and mental health regarding recent experience of sexual coercion. We observed significant gender differences in the findings. Male students over 23 years and who came from families where the educational level of the head of household was less than primary school had higher odds of having a recent experience of sexual coercion. Students with poor mental health were three times more likely to report sexual coercion, a finding that was significant for males and females. Alcohol consumption over the past 12 months had a significant association with recent experience of sexual coercion (OR crude 2.14, 95\% CI 1.383.32 ), the finding was significant for both males (OR crude 2.21, 95\% CI 1.07-4.55) and for females (OR crude 2.21, 95\% CI 1.07-4.55). The association between alcohol consumption on the occasion of sexual intercourse was significant with recent experiences of sexual coercion (OR crude 3.14, 95\% CI 1.84-5.37) and showed considerable gender differences. Females had a higher risk (OR crude $5.65,95 \%$ CI 2.24-14.22) compared to males (OR crude 2.53, 95\% CI 1.27-5.05).

Table 3 shows the multivariate analysis regarding the association between alcohol consumption in the last 12 months with recent experience of sexual coercion, which was found to be significant in the final model (OR adjusted 2.29, 95\% CI 1.40-3.72). The multivariate analysis indicated that there was possible confounding between alcohol consumption and poor mental health. It was also found that females older than 23 years were at a greater risk for being sexually coerced. Table 4 shows the multivariate association between alcohol consumption on the occasion of sexual intercourse and recent experiences of sexual coercion The association remained significant even after adjusting for confounders (OR adjusted 1.79, 95\% CI 1.05-.04). The analysis showed that that there was possible confounding between alcohol consumption and poor mental health and females were found to be at a higher risk of being recently sexually coerced.

To further investigate the association between alcohol consumption and recent experience of sexual coercion, we analysed whether mental health was an effect modifier (Tables 5 and 6) and found that frequent alcohol use on the occasion of sexual intercourse and poor mental health had a synergistic effect on recent experience of sexual coercion (Table 6).

\section{Discussion}

In this study among Ugandan university students, we found that those students, who frequently consumed alcohol or used it in relation to sex, had a higher risk of being subjected to sexual coercion. These associations were statistically significant even after adjusting for potential confounders. We also found a synergistic effect between frequent consumers of alcohol on the occasion of sexual intercourse and poor mental health with recent experience of sexual coercion. But, no synergy was found in the association between alcohol consumption in general during the past 12 months and poor mental health in its bearing on recent experience of sexual coercion.

From the current study we found that alcohol consumption in the last 12 months had an association with recent experience of sexual coercion. A possible explanation for 
Table 1 Prevalence of socio-demographic factors, alcohol consumption, mental health, and sexual coercion among Ugandan university students

\begin{tabular}{|c|c|c|c|c|c|}
\hline & & $\begin{array}{l}\text { All } \\
\text { n (\%) } \\
1954(\%)\end{array}$ & $\begin{array}{l}\text { Male } \\
\text { n (\%) } \\
1087(\%)\end{array}$ & $\begin{array}{l}\text { Female } \\
\text { n (\%) } \\
867(\%)\end{array}$ & $\begin{array}{l}x^{2} \\
p^{1}\end{array}$ \\
\hline \multirow[t]{3}{*}{ Age } & $\leq 22$ & $1042(55.5)$ & $521(49.6)$ & $521(63.1)$ & $<.001$ \\
\hline & $>22$ & $835(44.5)$ & $530(50.4)$ & $305(36.9)$ & \\
\hline & Missing & 77 & 36 & 41 & \\
\hline \multirow[t]{3}{*}{ Area of growing up } & Urban & $1067(55.1)$ & $551(51.2)$ & $516(60.1)$ & $<.001$ \\
\hline & Rural & $869(44.9)$ & $526(48.8)$ & $343(39.9)$ & \\
\hline & Missing & 18 & 10 & 8 & \\
\hline \multirow[t]{3}{*}{ Educational level of head of the household } & $>$ Primary education & $1382(72.7)$ & $730(68.9)$ & $652(77.5)$ & $<.001$ \\
\hline & $\leq$ Primary education & $518(27.3)$ & $329(31.1)$ & $189(22.5)$ & \\
\hline & Missing & 54 & 28 & 26 & \\
\hline \multirow[t]{3}{*}{ Importance of religion } & Major & $1232(63.5)$ & $650(60.3)$ & $582(67.5)$ & .001 \\
\hline & Minor & $708(36.5)$ & $428(39.7)$ & $280(32.5)$ & \\
\hline & Missing & 14 & 9 & 5 & \\
\hline \multirow[t]{3}{*}{ Mental health } & Good mental health & $920(50.4)$ & $549(54.5)$ & $371(45.5)$ & $<.001$ \\
\hline & Poor mental health & $904(49.6)$ & $459(45.5)$ & $445(54.5)$ & \\
\hline & Missing & 130 & 79 & 51 & \\
\hline \multirow[t]{3}{*}{ Experience of sexual coercion } & No & $1130(72.4)$ & $665(77.5)$ & $456(66.1)$ & $<.001$ \\
\hline & Yes & $431(27.6)$ & $193(22.5)$ & $238(33.9)$ & \\
\hline & Missing & 393 & 229 & 164 & \\
\hline \multirow[t]{3}{*}{ Early experience of sexual coercion ${ }^{2}$} & No & $1386(88.8)$ & $766(89.3)$ & $620(88.2)$ & .519 \\
\hline & Yes & $175(11.2)$ & $92(10.7)$ & $83(11.8)$ & \\
\hline & Missing & 393 & 229 & 164 & \\
\hline \multirow[t]{3}{*}{ Recent experience of sexual coercion ${ }^{2}$} & No & $1305(83.6)$ & $757(88.2)$ & $548(78.0)$ & $<.001$ \\
\hline & Yes & $256(16.4)$ & $101(11.8)$ & $155(22.0)$ & \\
\hline & Missing & 393 & 229 & 164 & \\
\hline \multirow[t]{4}{*}{ Alcohol consumed in the past 12 months } & Abstainers & $1017(56.2)$ & $514(49.9)$ & $503(64.5)$ & $<.001$ \\
\hline & Infrequent users & $632(34.9)$ & $403(39.1)$ & $229(29.4)$ & \\
\hline & Frequent users & $161(8.9)$ & $113(11.0)$ & $48(6.2)$ & \\
\hline & Missing & 144 & 57 & 87 & \\
\hline \multirow[t]{4}{*}{ Heavy episodic drinking (HED) } & Abstainers & $1017(58.0)$ & $514(51.9)$ & $503(66.1)$ & $<.001$ \\
\hline & Seldom HED & $530(30.3)$ & $326(32.9)$ & $204(26.8)$ & \\
\hline & Frequent HED & $205(11.7)$ & $151(15.2)$ & $54(7.1)$ & \\
\hline & Missing & 202 & 96 & 106 & \\
\hline \multirow[t]{3}{*}{ Alcohol on latest occasion of sexual intercourse $e^{3,4}$} & No & $360(72.9)$ & $227(70.7)$ & $133(76.9)$ & .168 \\
\hline & Yes & $134(27.1)$ & $94(29.3)$ & $40(23.1)$ & \\
\hline & Missing & 96 & 67 & 29 & \\
\hline \multirow[t]{3}{*}{ Alcohol consumption on the occasion of sexual intercourse $e^{3,4}$} & Seldom users & $391(79.0)$ & $245(76.6)$ & $146(83.4)$ & .084 \\
\hline & Frequent users & $104(21.0)$ & $75(23.4)$ & 29 (16.6) & \\
\hline & Missing & 95 & 68 & 27 & \\
\hline
\end{tabular}

${ }_{1} p$ value analysed in the table is based on sex.

${ }^{2}$ Only analyzed for those individuals who had experienced sexual coercion.

${ }^{3}$ Only analyzed for those who have consumed alcohol.

${ }^{4}$ Only analyzed for individuals who had had sexual intercourse. 
Table 2 Association (Crude Odds ratios, 95\% Confidence Interval) between socio-demographic variables, mental health, and alcohol consumption patterns with recent experience of sexual coercion among Ugandan university students

\begin{tabular}{|c|c|c|c|c|c|c|c|}
\hline & & \multicolumn{2}{|r|}{ All } & \multicolumn{2}{|r|}{ Male } & \multicolumn{2}{|c|}{ Female } \\
\hline & & n (\%) & OR $(95 \% \mathrm{Cl})$ & n (\%) & OR $(95 \% \mathrm{Cl})$ & n (\%) & OR (95\% Cl) \\
\hline \multirow[t]{2}{*}{ Age } & $\leq 22$ & $124(14.6)$ & 1 (Ref) & $34(8.1)$ & 1 (Ref) & $90(20.7)$ & 1 (Ref) \\
\hline & $>22$ & $124(19.0)$ & $1.37(1.04-1.80)$ & $64(15.6)$ & $2.08(1.34-3.23)$ & $60(24.8)$ & $1.26(.86-1.82)$ \\
\hline \multirow[t]{2}{*}{ Area of growing up } & Urban & $126(14.8)$ & 1 (Ref) & $43(9.9)$ & 1 (Ref) & $83(20.0)$ & 1 (Ref) \\
\hline & Rural & $127(18.2)$ & $1.28(.97-1.67)$ & $56(13.5)$ & $1.41(.93-2.16)$ & $71(25.2)$ & $1.35(.94-1.93)$ \\
\hline \multirow{2}{*}{$\begin{array}{l}\text { Educational level of } \\
\text { head of the household }\end{array}$} & > Primary education & $170(15.4)$ & 1 (Ref) & $59(10.2)$ & 1 (Ref) & $111(21.2)$ & 1 (Ref) \\
\hline & $\leq$ Primary education & $82(19.3)$ & $1.31(.98--1.75)$ & $42(16.0)$ & $1.67(1.09-2.55)$ & $40(24.8)$ & $1.22(.81-1.85)$ \\
\hline \multirow[t]{2}{*}{ Importance of religion } & Major & $153(15.8)$ & 1 (Ref) & $58(11.6)$ & 1 (Ref) & $95(20.4)$ & 1 (Ref) \\
\hline & Minor & $101(17.2)$ & $1.10(.84-1.45)$ & $42(12.0)$ & $1.04(.68-1.59)$ & $59(24.9)$ & $1.29(.89-1.87)$ \\
\hline \multirow[t]{2}{*}{ Mental health } & Good mental health & $68(8.9)$ & 1 (Ref) & $30(6.7)$ & 1 (Ref) & $38(12.1)$ & 1 (Ref) \\
\hline & Poor mental health & $180(23.9)$ & $3.21(2.38-4.33)$ & $66(17.1)$ & $2.90(1.84-4.57)$ & $114(30.9)$ & $3.24(2.16-4.86)$ \\
\hline \multirow{3}{*}{$\begin{array}{l}\text { Alcohol consumption in } \\
\text { the past } 12 \text { months }\end{array}$} & Abstainers & $125(14.8)$ & 1 (Ref) & $40(9.4)$ & 1 (Ref) & $85(20.3)$ & 1 (Ref) \\
\hline & Infrequent users & $78(15.5)$ & $1.05(.77-1.43)$ & $38(12.1)$ & $1.04(.68-1.59)$ & $40(21.1)$ & $1.33(.83-2.12)$ \\
\hline & Frequent users & $34(27.2)$ & $2.14(1.38-3.32)$ & 21 (23.6) & $2.21(1.07-4.55)$ & $13(36.1)$ & $2.97(1.65--5.35)$ \\
\hline \multirow{2}{*}{$\begin{array}{l}\text { Alcohol consumption on the } \\
\text { occasion of sexual intercourse }\end{array}$} & Infrequent users & $54(16.5)$ & 1 (Ref) & $29(14.4)$ & 1 (Ref) & 25 (19.8) & 1 (Ref) \\
\hline & Frequent users & $31(38.3)$ & $3.14(1.84-5.37)$ & $17(29.8)$ & $2.53(1.27-5.05)$ & $14(58.3)$ & $5.65(2.24-14.22)$ \\
\hline
\end{tabular}

Only analyzed among individuals who had had sexual intercourse.

${ }^{2}$ Only analyzed among individuals who had consumed alcohol.

this could be that in a university environment, where students socialize at bars or parties, risky alcohol consumption may lead to sexual coercion. A previous study suggests that there is a causal link between alcohol consumption at bars or parties, and the occurrence of sexual coercion [39]. It would be difficult to disentangle the direct effect of the alcohol consumed by the victim, from the effects associated with the setting, where the perpetrators are present [39].
We also found an association between alcohol consumption in relation to sex with recent experience of sexual coercion. This association can be explained by various mechanisms. At a behavioral or psychological level, alcohol may decrease the risk perception and the ability to communicate assertively, making an individual more vulnerable to being sexually victimized $[23,39,40]$. There are various theories that have been discussed in

Table 3 Association (Adjusted Odds Ratio, 95\% Confidence Interval) between alcohol consumption in the past 12 months and recent experience of sexual coercion among Ugandan university students

\begin{tabular}{|c|c|c|c|c|c|c|}
\hline & $\begin{array}{l}\text { Model } 1 \\
\text { OR }(95 \% \mathrm{Cl})\end{array}$ & $\begin{array}{l}\text { Model } 2^{1} \\
\text { OR }(95 \% \mathrm{Cl})\end{array}$ & $\begin{array}{l}\text { Model } 3^{2} \\
\text { OR }(95 \% \mathrm{Cl})\end{array}$ & $\begin{array}{l}\text { Model } 4^{3} \\
\text { OR }(95 \% \mathrm{Cl})\end{array}$ & $\begin{array}{l}\text { Model } 5^{4} \\
\text { OR }(95 \% \mathrm{Cl})\end{array}$ & $\begin{array}{l}\text { Model } 6^{5} \\
\text { OR }(95 \% \mathrm{Cl})\end{array}$ \\
\hline \multicolumn{7}{|l|}{ Alcohol consumption in the last 12 months } \\
\hline Abstainers & 1 (Ref) & 1 (Ref) & 1 (Ref) & 1 (Ref) & 1 (Ref) & 1 (Ref) \\
\hline Infrequent users & $.98(.71-1.36)$ & $1.09(.79-1.52)$ & $1.09(.79-1.52)$ & $1.11(.80-1.55)$ & $1.12(.80-1.56)$ & $1.02(.72-1.43)$ \\
\hline Frequent users & $2.12(1.34-3.33)$ & $2.62(1.64-4.18)$ & $2.61(1.63-4.17)$ & $2.68(1.67-4.29)$ & $2.73(1.70-4.39)$ & $2.29(1.40-3.72)$ \\
\hline Female & & $2.30(1.70-3.11)$ & $2.48(1.82-3.38)$ & $2.53(1.85-3.45)$ & $2.57(1.88-3.51)$ & $2.37(1.72-3.25)$ \\
\hline$>22$ years & & & $1.62(1.20-2.19)$ & $1.56(1.15-2.11)$ & $1.53(1.13-2.08)$ & $1.64(1.20-2.23)$ \\
\hline Rural & & & & $1.30(.96-1.76)$ & $1.21(.88-1.67)$ & $1.17(.84-1.62)$ \\
\hline Low educational level of head of household & & & & & $1.25(.88-1.76)$ & $1.08(.76-1.54)$ \\
\hline Poor mental health & & & & & & $3.14(2.25-4.37)$ \\
\hline
\end{tabular}

${ }^{1}$ Model 2 adjusted for sex.

${ }^{2}$ Model 3 adjusted for sex and age.

${ }^{3}$ Model 4 adjusted for sex, age, and area of origin.

${ }^{4}$ Model 5 adjusted for sex, age, and area of origin and educational level of head of household.

${ }^{5}$ Model 6 adjusted for sex, age, and area of origin and educational level of head of household, and mental health. 
Table 4 Association (adjusted odds ratio, 95\% confidence interval) between alcohol consumption on the occasion of sexual intercourse and recent experience of sexual coercion among Ugandan university students

\begin{tabular}{|c|c|c|c|c|c|c|}
\hline & $\begin{array}{l}\text { Model } 1 \\
\text { OR }(95 \% \mathrm{Cl})\end{array}$ & $\begin{array}{l}\text { Model } 2^{1} \\
\text { OR }(95 \% \mathrm{Cl})\end{array}$ & $\begin{array}{l}\text { Model } 3^{2} \\
\text { OR }(95 \% \mathrm{Cl})\end{array}$ & $\begin{array}{l}\text { Model } 4^{3} \\
\text { OR }(95 \% \mathrm{Cl})\end{array}$ & $\begin{array}{l}\text { Model } 5^{4} \\
\text { OR }(95 \% \mathrm{Cl})\end{array}$ & $\begin{array}{l}\text { Model } 6^{5} \\
\text { OR }(95 \% \mathrm{Cl})\end{array}$ \\
\hline \multicolumn{7}{|l|}{$\begin{array}{l}\text { Frequency of alcohol on the } \\
\text { occasion of sexual intercourse }\end{array}$} \\
\hline Infrequent users & 1 (Ref) & 1 (Ref) & 1 (Ref) & 1 (Ref) & 1 (Ref) & 1 (Ref) \\
\hline Frequent users & $2.95(1.7-5.12)$ & $3.18(1.82-5.57)$ & $3.14(1.79-5.51)$ & $3.17(1.81-5.57)$ & $3.21(1.82-5.65)$ & $2.78(1.56-4.97)$ \\
\hline Female & & $1.88(1.14-3.10)$ & $1.97(1.18-3.29)$ & $2.01(1.20-3.37)$ & $2.03(1.21-3.40)$ & $1.79(1.05-3.04)$ \\
\hline$>22$ years & & & $1.36(.82-2.25)$ & $1.34(.81-2.23)$ & $1.31(.79-2.19)$ & $1.43(.85-2.42)$ \\
\hline Rural & & & & $1.14(.68-1.90)$ & $1.09(.64-1.86)$ & $.95(.55-1.65)$ \\
\hline Low educational level of head of household & & & & & $1.19(.65-2.18)$ & $1.14(.61-2.11)$ \\
\hline Poor mental health & & & & & & $2.72(1.52-4.85)$ \\
\hline
\end{tabular}

${ }^{1}$ Model 2 adjusted for sex.

${ }^{2}$ Model 3 adjusted for sex and age.

${ }^{3}$ Model 4 adjusted for sex, age, and area of origin.

${ }^{4}$ Model 5 adjusted for sex, age, and area of origin and educational level of head of household.

${ }^{5}$ Model 6 adjusted for sex, age, and area of origin and educational level of head of household, and mental health.

literature regarding the association between alcohol and sex, like sexual disinhibition or alcohol myopia theory $[41,42]$ which explains that due to the high consumption of alcohol the person might not be able to identify the potential dangers, including the risk of being sexually coerced.

However, even if these theories explain some behavior, the perpetrators are responsible for the act of sexual coercion, regardless of whether they were intoxicated or not [23]. In a coercive situation the victim is left without any decision making latitude which can lead to unsafe sex that can further result in unintended pregnancy or an STI. Studies have shown that women who have consumed alcohol were more likely to report that they would respond passively to unwanted sexual advances [43] and would be able to employ less effective refusal strategies when they face sexual aggression than sober women [23]. Therefore, it is important to empower women themselves, by identifying actions that may put them at a risk.

Alcohol consumption may also act as a coping mechanism to reduce psychological distress among victims, which may also be lead to abuse over time [44]. In our analyses, poor mental health confounded the association between alcohol use and sexual coercion. Still, alcohol use indicators remained statistically significant, suggesting that alcohol consumption and poor mental health represent two independent causal mechanisms. In addition, we also found a synergistic effect between frequent alcohol consumption on the occasion of sexual intercourse and poor mental health, regarding the risk for recent experience of sexual coercion.

Among gender differences, females who consumed alcohol were at a higher risk of being sexually coerced compared to males. There is a discrepancy in the existing gender norms regarding drinking patterns in Uganda. Consuming alcohol is related to masculinity among young boys and is associated with lack of respect among girls [45]. The cultural gender stereotypes consider women who drink to be sexually available and more likely to engage in sexual intercourse than women who abstain $[39,46]$. These stereotypes are accentuated by gender imbalances in Uganda, men have the power to control women's behavior, including the sexual decision making

Table 5 Analysis of effect modification between alcohol consumption in the last 12 months and mental health regarding recent experience of sexual coercion in a sample of Ugandan university students $(n=1954)$, presented as adjusted odds ratios (OR) with $95 \%$ confidence intervals $(\mathrm{CI})$

\begin{tabular}{|c|c|c|c|c|}
\hline & n (\%) & Cases & OR $(95 \% \mathrm{Cl})$ & \\
\hline Infrequent user of alcohol and good mental health & $811(47.5)$ & 52 & 1 (Ref) & \\
\hline Infrequent user of alcohol and poor mental health & $744(43.5)$ & 145 & $3.57(2.54-5.01)$ & \\
\hline Frequent user of alcohol and good mental health & $60(3.5)$ & 10 & $3.24(1.52-6.89)$ & \\
\hline Frequent user of alcohol and poor mental health & $94(5.5)$ & 23 & $5.20(2.95-9.16)$ & Synergy index $=0.87$ \\
\hline Missing & 245 & & & \\
\hline
\end{tabular}


Table 6 Analysis of effect modification between alcohol consumption on the occasion of having sexual intercourse and mental health regarding recent experience of sexual coercion in a sample of Ugandan university students $(n=1954)$, presented as adjusted Odds Ratios (OR) with $95 \%$ Confidence Intervals (CI)

\begin{tabular}{|c|c|c|c|c|}
\hline & n (\%) & Cases & OR $(95 \% \mathrm{Cl})$ & \\
\hline Infrequent user of alcohol on the occasion of sexual intercourse and good mental health & 176 (37.3) & 13 & 1 (Ref) & \\
\hline Infrequent of alcohol on the occasion of sexual intercourse and poor mental health & $197(41.7)$ & 40 & $3.05(1.56-5.96)$ & \\
\hline Frequent user of alcohol on the occasion of sexual intercourse and good mental health & $31(6.6)$ & 5 & $2.57(.83-8.00)$ & \\
\hline Frequent user of alcohol on occasion of sexual intercourse and poor mental health & $68(14.4)$ & 24 & $8.24(3.77-18.03)$ & Synergy index $=2.00$ \\
\hline Missing & 118 & & & \\
\hline
\end{tabular}

process. There is evidence from previous research that alcohol consumption facilitates coercive acts because of the alcohol myopia mechanism, which render them less sensitive to the victim's signs of refusal, which can accentuate the likelihood of sexual or physical violence $[23,26]$.

\section{Strengths and limitations}

The survey, on which our study was based, targeted all students at MUST, with a total response rate of $72 \%$, which leaves room for selection bias. However, the reasons for non-participation do not seem to be linked to the main exposures nor to the outcome, since they could be due to many reasons, which might include logistic circumstances, length of the questionnaire, or unwillingness to participate due to the sensitive questions in the survey. But, we do not have any data to support those assumptions. Strength of our study was that we focused on the drinking patterns of victims and their association with recent experience of sexual coercion. A limitation of our study stems from its cross-sectional design, which does not permit us to safely judge the direction of causation between the independent variables and the self-reported experiences of sexual coercion. A reverse causation could not be ruled out; on the contrary it seems plausible, but we find it unlikely to be the major mechanism behind our findings. Another potential limitation of our study was that there was no information in the questionnaire on the drinking patterns of the perpetrators of sexual coercion. The prevalence of students who were exposed to sexual coercion and alcohol consumption may have been higher than reported in the questionnaire, since socially undesirable behaviors are usually underreported. However, we believe that if this were so, it would bias the differences we found towards the null, since it would more likely represent a case of non-differential misclassification than one of differential misclassification. In our analyses we adjusted for the most obvious confounding factors, including those that had little impact on the associations that we determined.

\section{Conclusion}

This study concludes that there is an association between alcohol consumption patterns and sexual coercion among Ugandan university students. Universities should consider alcohol use prevention under their policy framework, as it could reduce the potential risk of sexual coercion, in addition to other harmful effects of alcohol abuse. It is crucial for universities to develop institutional capacity for handling cases of sexual coercion. One consideration can be to conduct training workshops that involve both men and women, in order to create awareness regarding the existing gender inequalities, and the importance of respecting each other's sexual rights. These trainings can be used to inform on the process of reporting cases of coercion and the consequences for the perpetrators. This can help in reducing negative reproductive health outcomes such as teenage pregnancy and sexually transmitted infections. For future research we would like to suggest that it might be beneficial to conduct longitudinal research to confirm the association between alcohol consumption and sexual coercion.

\section{Competing interests}

The authors declare that they have no competing interests.

\section{Authors' contributions}

DM contributed to the data collection, study design, conducted the statistical analysis, analysed the data and drafted the manuscript. PO contributed to the study design, data analysis, interpretation of results and in the writing of the manuscript. AA designed the study and developed the protocol, collected the data, contributed to the data analysis and in writing of the manuscript. MS contributed to the data analysis and in the writing of the manuscript. All authors have read and approved the final manuscript.

\section{Acknowledgments}

This study was supported by grants from the Swedish International Development Cooperation Agency (Sida)

\section{Author details}

'Social Medicine and Global Health, Department of Clinical Sciences, Lund University, Malmö, Sweden. ${ }^{2}$ Department of Pediatrics, Centre for Adolescent Health, Royal Children's Hospital, Murdoch Children's Research Institute, University of Melbourne, Victoria, Australia. ${ }^{3}$ Social Medicine and Global Health, Department of Clinical Sciences, Clinical Research Centre, Lund University, Jan Waldenströms gata 35, House 28, Floor 12, 20502 Malmö, Sweden.

Received: 19 June 2013 Accepted: 8 January 2014 Published: 16 January 2014 


\section{References}

1. Watts C, Zimmerman C: Violence against women: global scope and magnitude. Lancet 2002, 359(9313):1232-1237.

2. Adams-Curtis LE, Forbes GB: College women's experiences of sexual coercion: a review of cultural, perpetrator, victim, and situational variables. Trauma Violence Abuse 2004, 5(2):91-122.

3. Jejeebhoy S, Bott S: Non-consensual sexual experiences of young people: A review of the evidence from developing countries. In Regional Working papers. New Delhi: Population Council; 2003.

4. Erulkar AS: The experience of sexual coercion among young people in Kenya. Int Fam Plan Perspect 2004, 30(4):182-189.

5. Koenig MA, Zablotska I, Lutalo T, Nalugoda F, Wagman J, Gray R: Coerced first intercourse and reproductive health among adolescent women in Rakai, Uganda. Int Fam Plan Perspect 2004, 30(4):156-163.

6. Messman-Moore TL, Ward RM, Brown AL: Substance use and PTSD symptoms impact the likelihood of rape and revictimization in college women. J Interpers Violence 2009, 24(3):499-521.

7. Davies M, Rogers P: Perceptions of male victims in depicted sexual assaults: A review of the literature. Aggress Violent Beh 2006, 11(4):367-377

8. Hines DA: Predictors of sexual coercion against women and men: a multilevel, multinational study of university students. Arch Sex Behav 2007, 36(3):403-422.

9. Ybarra ML, Bull SS, Kiwanuka J, Bangsberg DR, Korchmaros J: Prevalence rates of sexual coercion victimization and perpetration among Uganda adolescents. AIDS Care 2012, 24(11):1392-1400.

10. Glover EK, Bannerman A, Pence BW, Jones H, Miller R, Weiss E, NerquayeTetteh J: Sexual health experiences of adolescents in three Ghanaian towns. Int Fam Plan Perspect 2003, 29(1):32-40

11. Somse P, Chapko MK, Hawkins RV: Multiple sexual partners: results of a national HIV/AIDS survey in the Central African Republic. AIDS 1993, 7(4):579-583.

12. Rwenge M: Sexual risk behaviors among young people in Bamenda, Cameroon. Int Fam Plan Perspect 2000, 26(3):118-123.

13. Agardh A, Odberg-Pettersson K, Ostergren PO: Experience of sexual coercion and risky sexual behavior among Ugandan university students. BMC Public Health 2011, 11:527.

14. EAC/EALP: HIV Sero Behavioural study in six universities in Uganda. Kampala: SIDA; 2010.

15. Gross AM, Winslett A, Roberts M, Gohm CL: An examination of sexual violence against college women. Violence Against Women 2006, 12(3):288-300.

16. Chan KL, Straus MA, Brownridge DA, Tiwari A, Leung WC: Prevalence of dating partner violence and suicidal ideation among male and female university students worldwide. J Midwifery Womens Health 2008, 53(6):529-537.

17. Moore AM, Awusabo-Asare K, Madise N, John-Langba J, Kumi-Kyereme A: Coerced first sex among adolescent girls in sub-Saharan Africa: prevalence and context. Afr J Reprod Health 2007, 11(3):62-82.

18. Moore AM, Biddlecom AE, Zulu EM: Prevalence and meanings of exchange of money or gifts for sex in unmarried adolescent sexual relationships in sub-Saharan Africa. Afr J Reprod Health 2007, 11(3):44-61.

19. Uganda Ministry of Health and ICF International: 2011 Uganda Aids Indicator Survey: Key Findings. Claverton, Maryland, USA; 2012. Available at http:// health.go.ug/docs/UAIS_2011_KEY_FINDINGS.pdf Accessed 5 June 2013.

20. Koenig MA, Lutalo T, Zhao F, Nalugoda F, Kiwanuka N, Wabwire-Mangen F, Kigozi G, Sewankambo N, Wagman J, Serwadda D, et al: Coercive sex in rural Uganda: prevalence and associated risk factors. Soc Sci Med 2004, 58(4):787-798

21. Stafström M, Agardh A: Socio economic determinants for alcohol consumption and heavy episodic drinking in a Ugandan student population. Int J Alcohol Drug Re 2012, 1(1):57-67.

22. Benson BJ, Gohm CL, Gross AM: College women and sexual assault: The role of sex-related alcohol expectancies. J Fam Violence 2007, 22(6):341-351.

23. Abbey A: Alcohol-related sexual assault: a common problem among college students. J Stud Alcohol Suppl 2002, 14:118-128.

24. Krebs CP, Lindquist CH, Warner TD, Fisher BS, Martin SL: College women's experiences with physically forced, alcohol- or other drug-enabled, and drug-facilitated sexual assault before and since entering college. J Am Coll Health 2009, 57(6):639-647.
25. Uganda Youth Development Link (UYDEL): State of Alcohol abuse in Uganda "Young people drinking deeper in poverty"; 2008. Available at http://www. uydel.org/downloads/State\%20of\%20Alcohol\%20Abuse\%20in\%20Uganda20110706-161512.pdf Accessed 10 July 2013.

26. Zablotska IB, Gray RH, Koenig MA, Serwadda D, Nalugoda F, Kigozi G, Sewankambo N, Lutalo T, Wabwire Mangen F, Wawer M: Alcohol use, intimate partner violence, sexual coercion and HIV among women aged 15-24 in Rakai, Uganda. AIDS Behav 2009, 13(2):225-233.

27. Critchlow B: The powers of John Barleycorn. Beliefs about the effects of alcohol on social behavior. Am Psychol 1986, 41(7):751-764.

28. Steele CM, Josephs RA: Alcohol myopia. Its prized and dangerous effects. Am Psychol 1990, 45(8):921-933.

29. Brown SA, Creamer VA, Stetson BA: Adolescent Alcohol Expectancies in Relation to Personal and Parental Drinking Patterns. J Abnorm Psychol 1987, 96(2):117-121.

30. Agardh A, Emmelin M, Muriisa R, Ostergren PO: Social capital and sexual behavior among Ugandan university students. Glob Health Action 2010, 3:5432.

31. Agardh A, Ostergren PO, Liljestrand J: Sexual patterns among youth in Mbarara district, Uganda with a special focus on coercion and power relations. In The XV International conference on AIDS. Bangkok, Thailand: International AIDS society; 2004.

32. Derogatis LR, Lipman RS, Rickels K, Uhlenhuth EH, Covi L: The Hopkins Symptom Checklist (HSCL): a self-report symptom inventory. Behav Sci 1974, 19(1):1-15.

33. Ventevogel P, De Vries G, Scholte WF, Shinwari NR, Faiz H, Nassery R, van den Brink W, Olff M: Properties of the Hopkins Symptom Checklist-25 (HSCL-25) and the Self-Reporting Questionnaire (SRQ-20) as screening instruments used in primary care in Afghanistan. Soc Psychiatry Psychiatr Epidemiol 2007, 42(4):328-335.

34. Lee B, Kaaya SF, Mbwambo JK, Smith-Fawzi MC, Leshabari MT: Detecting depressive disorder with the Hopkins Symptom Checklist-25 in Tanzania. Int J Soc Psychiatry 2008, 54(1):7-20.

35. Lundberg P, Cantor-Graae E, Rukundo G, Ashaba S, Ostergren PO: Urbanicity of place of birth and symptoms of psychosis, depression and anxiety in Uganda. Br J Psychiatry 2009, 195(2):156-162.

36. Lewin B: Sex I Sverige, Om Sexual- Livet I. In Sex in Sweden, About sexual life in Sweden. Edited by Lewin B. Stockholm: Statens folkhalsoinstitut; 1999.

37. Mehra D, Agardh A, Petterson KO, Ostergren PO: Non-use of contraception: determinants among Ugandan university students. Glob Health Action 2012, 5:18599.

38. Greenland S, Rothman KJ: In Modern Epidemiology. 2nd edition. Edited by Greenland S, Rothman KJ. Philadelphia, USA: Lippincott-Raven; 1998:329-342.

39. Testa M, Parks KA: The role of women's alcohol consumption in sexual victimization. Aggress Violent Beh 1996, 1(3):217-234.

40. Testa M, Vanzile-Tamsen C, Livingston JA, Buddie AM: The role of women's alcohol consumption in managing sexual intimacy and sexual safety motives. J Stud Alcohol 2006, 67(5):665-674.

41. Monks SM, Tomaka J, Palacios R, Thompson SE: Sexual victimization in female and male college students: examining the roles of alcohol use, alcohol expectancies, and sexual sensation seeking. Subst Use Misuse 2010, 45(13):2258-2280.

42. Cooper ML: Does drinking promote risky sexual behavior? A complex answer to a simple question. Curr Dir Psychol Sci 2006, 15(1):19-23.

43. Davis KC, George WH, Norris J: Women's responses to unwanted sexual advances: The role of alcohol and inhibition conflict. Psychol Women Quart 2004, 28(4):333-343.

44. Miranda R Jr, Meyerson LA, Long PJ, Marx BP, Simpson SM: Sexual assault and alcohol use: exploring the self-medication hypothesis. Violence Vict 2002, 17(2):205-217.

45. Kafuko A, Bukuluki P: Qualitative research in Uganda on Knowledge, attitudes and practices concerning alcohol. USAID; 2008. Available at http://www. k4health.org/sites/default/files/Alcohol\%20Study\%20Report\%20FINAL\% 20March\%2013th.pdf Accessed 15 July 2013.

46. George WH, Gournic SJ, Mcafee MP: Perceptions of postdrinking female sexuality - effects of gender, beverage choice, and drink payment. J Appl Soc Psychol 1988, 18(15):1295-1317.

doi:10.1186/1742-4755-11-7

Cite this article as: Mehra et al:: Is drinking alcohol associated with sexual coercion among Ugandan university students? a cross-sectional study. Reproductive Health 2014 11:7. 